\title{
A modeling analysis of grounding resistance and sea surface potential on the jacket foundation offshore wind turbines
}

\author{
Shiqi Tao, Xiaoqing Zhang, and Yaowu Wang \\ Beijing Jiaotong University, Department of Electrical Engineering, No.3 Shangyuancun Haidian District 100044, Beijing, the People's \\ Republic of China
}

\begin{abstract}
Offshore wind turbines (WTs) are frequently exposed to the risk from lightning, storm, and waves. As a kind of fixed foundations, jacket foundation can effectively reduce the correlatively risk and loss. In order to provide more information about the lightning protection of jacket foundation, a simulation model has been built by simplifying the hollow steel tubes into a series of solid steel cylinders. And some conclusions on the grounding resistance of jacket foundation have been summarized in this paper by using the GSSAS (Grounding System Safe Analysis Software). According to the simulation results, the actual influential factors of grounding resistance, including the depth of seawater, the thickness of clay layer and the resistivity of gravel layer, have been analysed and compared. It is found that the grounding resistance is influenced most severely by the depth of seawater. In addition, the values of sea surface potential have been calculated by the software GSSAS and the three-dimensional diagrams of potential distribution have been mapped out.
\end{abstract}

\section{Introduction}

The common foundation structures of offshore wind turbines are the monopile and gravity foundation, but they are generally adapted for the depths of seawater about $0 \sim 15 \mathrm{~m}$ [1]. In order to install offshore WTs in deeper seawater where winds can be stronger and steadier, a firmer foundation like the jacket foundation is needed [2]. As one of the fixed foundations, jacket foundation can effectively reduce the damage from bad marine environment. Offshore WTs are especially susceptible to lightning strikes due to their height, distinctive shape and exposed location [3]. When the offshore WTs are struck by lightning, lightning current often flows through the blade, nacelle, tower, and foundation. Jacket foundation is soaked in the seawater, and the resistivity of seawater is far less than that of soil. The seawater has a beneficial influence on dissipating the lightning current, so offshore WTs usually utilize jacket foundations as the natural grounding bodies [4]. The grounding resistance and sea surface potential of jacket foundation need to be closely concerned in the electrical design and protection. At present, it is very difficult that making the grounding measurement in actual seawater, and the requirements of grounding resistance of offshore WTs are based on the existing onshore WTs standards [5-8] or own request of turbine manufactures that cannot reach a unified specification [9-10]. Therefore, it is necessary to explore the grounding resistance and sea surface potential of offshore WTs.
The multi-layer structure below sea level is taken into account and the simulation model of jacket foundation has been built by using professional software GSSAS [11-12]. GSSAS is employed to compute the value of grounding resistance according to the influential factors and it is also used to draw the three-dimensional distribution diagrams of sea surface potential. According to the environmental characteristic in China, the various influential factors have been considered, such as the depth of seawater, the thickness of clay layer, the resistivity of gravel and so on.

Calculation data and simulation results show that the value of grounding resistance and the distribution of sea surface potential are mainly affected by the depth of seawater, the thickness of clay layer and the resistivity of gravel. Additional, the marine environment in different countries and regions is different, and the values of grounding resistance need to be carefully studied according to local conditions.

\section{Structural parameters and simulation model}

As shown in Fig. 1(a), the jacket foundation consists of ladder, marine fender, jacket and piles [13-14]. In offshore engineering, the support structures are typically classified as $\mathrm{K}-, \mathrm{X}$-braces according to the geometrical shape [15]. This paper selected the four-leg jacket with three levels of X-braces and cross braces. The jacket foundation is a space frame composed of steel circular hollow sections. A concrete deck is positioned on the top of jacket and serves as a support platform for the tower. 
The medium space below the sea level is divided into the three layers, namely seawater layer, clay layer and gravel layer. According to Fig. 1(b), the depth of seawater and the thicknesses of clay layer are denoted by $h_{0}$ and $h_{1}$, the buried depth of pile is represented by $h_{1}+h_{2}$, and the resistivity of seawater, clay and gravel are defined by $\rho_{0}$, $\rho_{1}$ and $\rho_{2}$, respectively. The depth of seawater will vary due to rising and falling tides, and the resistivity of seawater is approximately taken as $1 \Omega \cdot \mathrm{m}$. Other relevant data are given in Table.1.

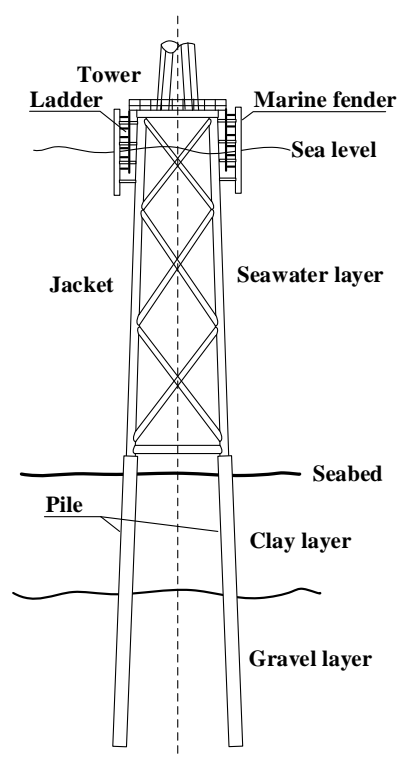

(a)

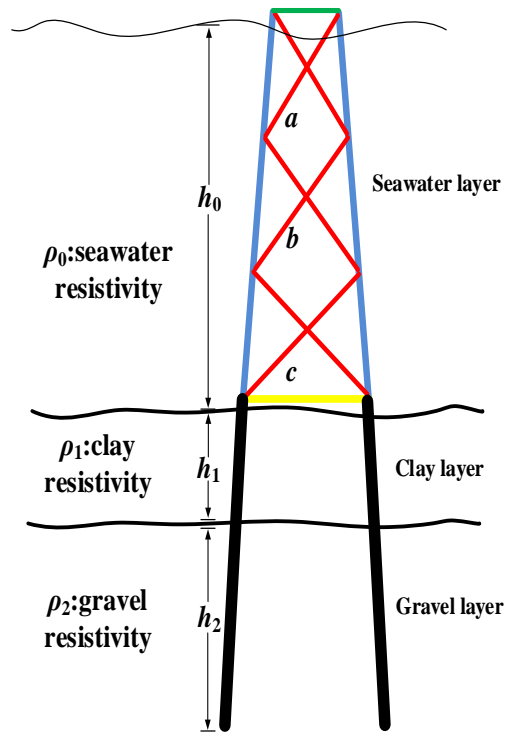

(b)

Fig. 1. Jacket foundation. (a) Structure diagram of jacket foundation, (b) Schematic diagram of jacket foundation.

Table 1. Data of the actual influential factors.

\begin{tabular}{|c|c|}
\hline Parameter & Range \\
\hline$h_{0}(\mathrm{~m})$ & $0 \sim 30$ \\
\hline$h_{1}(\mathrm{~m})$ & $10 \sim 30$ \\
\hline$h_{2}(\mathrm{~m})$ & 20 \\
\hline$\rho_{0}(\Omega \cdot \mathrm{m})$ & $1 \sim 5$ \\
\hline$\rho_{1}(\Omega \cdot \mathrm{m})$ & $10 \sim 150$ \\
\hline$\rho_{2}(\Omega \cdot \mathrm{m})$ & $500 \sim 4000$ \\
\hline
\end{tabular}

Properties of an actual jacket foundation are shown as described in Fig. 1(b) and Table. 2 [16]. On the basis of the data listed here, the simulation model of jacket foundation is further built for analysing the grounding resistance and the sea surface potential of the offshore WTs.

Table 2. Properties of jacket members (in Fig 1(b)).

\begin{tabular}{|c|c|c|c|c|}
\hline $\begin{array}{l}\text { Color in } \\
\text { Fig. 1(b) }\end{array}$ & $\begin{array}{l}\text { Outer } \\
\text { diameter } \\
(\mathrm{m})\end{array}$ & $\begin{array}{l}\text { Thickness } \\
(\mathrm{m})\end{array}$ & $\begin{array}{l}\text { Equivalent } \\
\text { diameter } \\
(\mathrm{m})\end{array}$ & $\begin{array}{l}\text { Length of } \\
\text { conductor } \\
(\mathrm{m})\end{array}$ \\
\hline green & 0.72 & 0.041 & 0.33 & 10 \\
\hline red $(a, b, c)$ & 0.80 & 0.022 & 0.25 & $15,18,21$ \\
\hline blue & 1.81 & 0.035 & 0.50 & 30.8 \\
\hline yellow & 1.0 & 0.021 & 0.28 & 20 \\
\hline black & 2.08 & 0.060 & 0.70 & 30 \\
\hline
\end{tabular}

From the requirement of analyzing the grounding resistance by GSSAS, the simulation model has been built by simplifying the hollow steel tubes into a series of solid steel cylinders, as shown in Fig. 3(a). The equivalent diameters and lengths of conductors can be shown in Table. 2, so the simulation model is built for the jacket foundation in Fig. 3(b). Subsequently, the grounding resistance and the sea surface potential can be calculated and analysed by GSSAS.

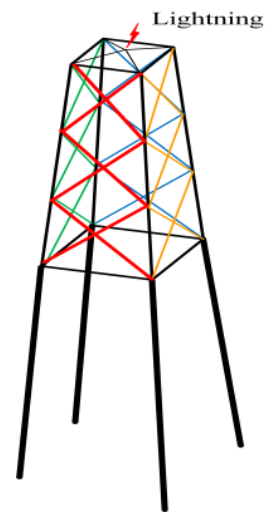

(a)

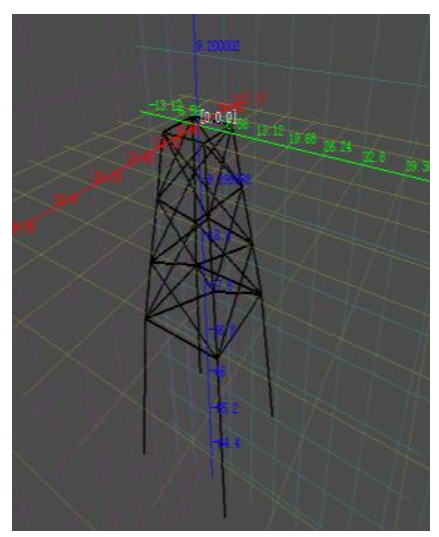

(b)

Fig. 2. Model of jacket foundation. (a) Equivalent model, (b) GSSAS simulation model. 


\section{Mainly influential factors of the grounding resistance}

\subsection{The depth of seawater}

The offshore WTs with different distances to the coast may locate at different sea area. Even for the same offshore WT, it also locates at a variable seawater depth due to rising and falling tides. When $h_{1}=10 \mathrm{~m}$ and $\rho_{2}=1000 \Omega \cdot \mathrm{m}$, Fig. 3 shows the relationships between the grounding resistance $R$ and the depth of seawater $h_{0}$ in different values of the resistivity of clay layer $\rho_{1}$.

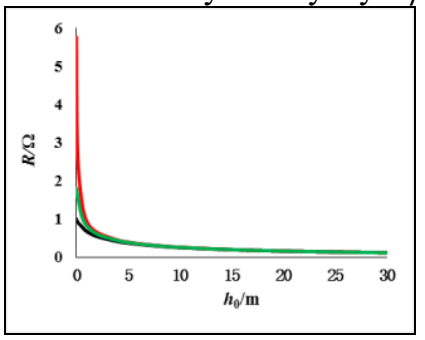

Fig. 3. $R-h_{0}$ curves at the different values of $\rho_{1}: \rho_{1}=10 \Omega \cdot \mathrm{m}$ (black), $30 \Omega \cdot \mathrm{m}$ (green), $150 \Omega \cdot \mathrm{m}$ (red).

According to Fig. 3 , in the process of $h_{0}$ increasing from 0 to $2 \mathrm{~m}$, the decreasing in the values of $R$ are remarkable in the different values of $\rho_{1}$. After $h_{0}$ is greater than $5 \mathrm{~m}, R$ becomes less than $0.4 \Omega$ and decreases slowly with increase in $h_{0}$. In extreme cases, such as the offshore WTs are quite close from the coast or the seawater is in the period of falling tide, the max value of grounding resistance $R$ will exceed $4 \Omega$ [17].

\subsection{The thickness of clay layer}

Fig. 4 shows the curves of $R$ varying with $h_{1}$ at different $h_{0}$, where $\rho_{1}=50 \Omega \cdot \mathrm{m}$ and $\rho_{2}=1000 \Omega \cdot \mathrm{m}$. The jacket foundations may be installed in the different clay layer thicknesses according to the different marine environment, so it is a certain significance to inspect the effect of $h_{1}$ on $R$.

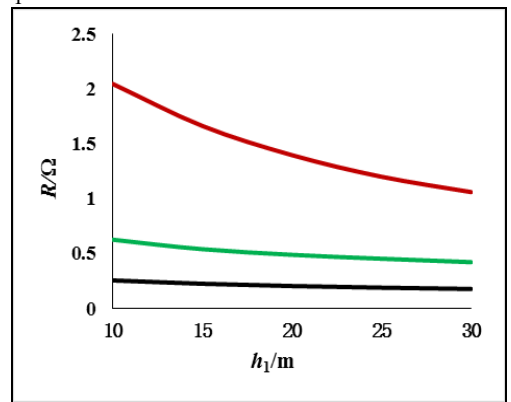

Fig. 4. $R$ - $h_{1}$ curves at the different seawater depths $h_{0}: h_{0}=0 \mathrm{~m}$ (red), $2 \mathrm{~m}$ (green), $10 \mathrm{~m}$ (black).

As seen from Fig. 4 , the tendency that $R$ decreases with $h_{1}$ gradually becomes slow with increase in $h_{0} . R$ is affected by $h_{1}$ more easily when $h_{0}<2 \mathrm{~m} ; R$ remains basically unchanged it means the degree that $h_{1}$ effects $R$ decreases when $h_{0} \geq 2 \mathrm{~m}$. The reason for this is that the resistivity of seawater is much less than that of clay and gravel. When the seawater reaches a certain depth, $R$ only depends on the resistivity of seawater, while the thickness of clay layer has almost no effect on $R$.

\subsection{The resistivity of gravel}

In terms of the actual range of the gravel resistivity, the curves of $R$ varying with $\rho_{2}$ at different $h_{0}$ are shown in Fig. 5. At this time, $\rho_{1}$ and $h_{1}$ are taken as $50 \Omega \cdot \mathrm{m}$ and 10 $\mathrm{m}$, respectively.

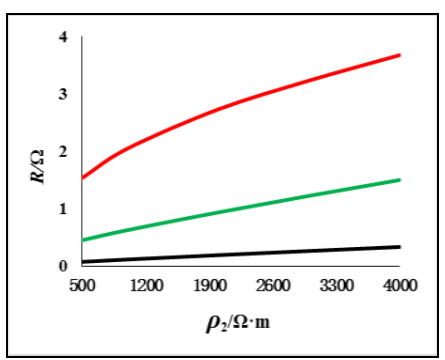

Fig. 5. $R-\rho_{2}$ curves at the different seawater depths $h_{0}: h_{0}=0 \mathrm{~m}$ (red), $2 \mathrm{~m}$ (green), $10 \mathrm{~m}$ (black).

Fig. 5 demonstrates that $R$ increases with $\rho_{2} . R$ is affected by $\rho_{2}$ more obvious when $h_{0}<2 \mathrm{~m}$, but the growth rate becomes lower and lower with increase of $h_{0}$. As the depth of seawater $h_{0}$ increases, $R$ is mainly governed by $\rho_{0}$, and $\rho_{2}$ will gradually lose its influence.

\section{Distribution of the potential on the sea surface}

When the offshore WT is injected by lightning current, the current usually flows through the blade, nacelle, tower and jacket foundation. Finally, the current is dissipated into the seawater and soil. In this process, the sea surface potential will be raised for the existence of grounding resistance which may cause back flash to the devices installed inside the tower [18-19]. At the same time, the electromagnetic field will be produced inside the tower by lightning current; the potential will be induced on the signal lines and power lines by means of radiation, induction and coupling. The high peak value of potential and sharp slope of waveform will also destroy electric and electronic devices of the offshore WTs. In this paper, when $h_{0}=10 \mathrm{~m}, h_{1}=15 \mathrm{~m}, \rho_{0}=1 \Omega \cdot \mathrm{m}$, $\rho_{1}=150 \Omega \cdot \mathrm{m}$ and $\rho_{2}=1000 \Omega \cdot \mathrm{m}$, the value of grounding resistance $R$ is $0.227 \Omega$ by calculation. According to these parameters, the distribution of potential on the sea surface can be obtained by GSSAS, as shown in Fig. 6 .

In Fig. 6, the blue vertical axis indicates the value of sea surface potential. When the peak value of injected current is $100 \mathrm{kA}$, the variation range of potential is $19522 \sim 22694 \mathrm{~V}$. Changing the mainly influential factors of grounding resistance will change the potential distribution: the maximum value of potential will decrease with the increase of the seawater depth or the clay layer thickness; the maximum value will increase with the increase of the gravel resistivity. The variation of potential on the sea surface is consistent with that of the grounding resistance. If an offshore WT is struck by lightning, the jacket foundation will be surrounded by 
the virtual curve of potential on the sea surface, and the high potential may be quite dangerous for people and other offshore WTs.

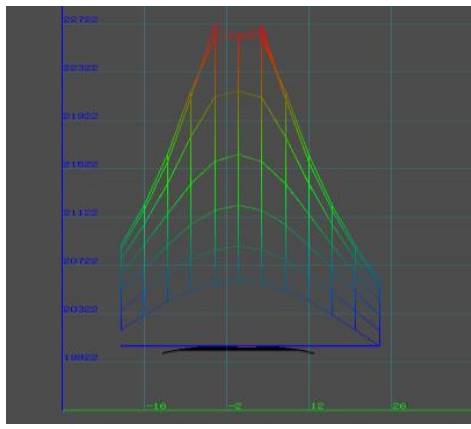

(a)

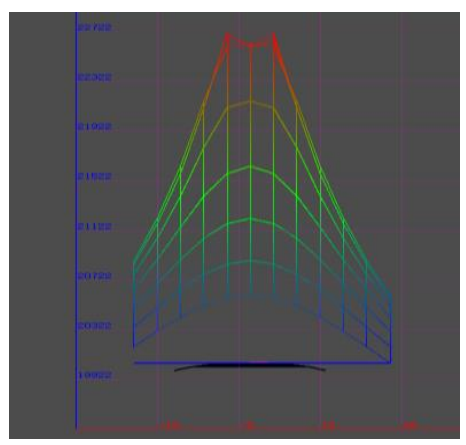

(b)

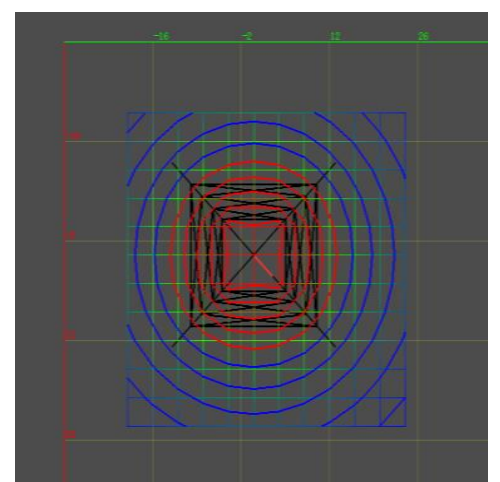

(c)

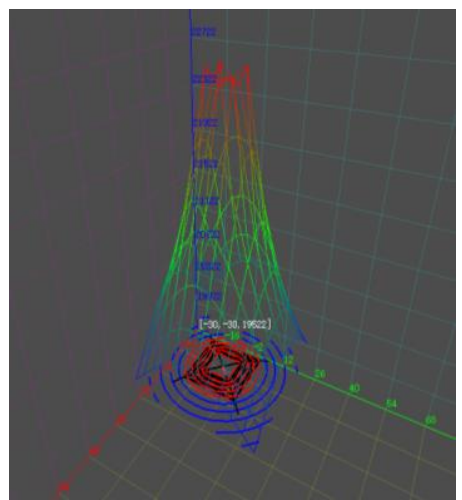

(d)

Fig. 6. Distribution diagrams of the potential on the sea surface. (a) Main view, (b) Left view, (c) Top view, (d) Perspective view.

\section{Conclusions}

In this paper, the grounding resistance and the potential distribution on the sea surface of the jacket foundation offshore WT have been studied. Some rules can be summarized, which could play a reference role for the lightning protection design of the offshore WTs. By using the professional GSSAS, the simulation research takes account of the typical factors that actually influence the value of grounding resistance. The depth of seawater is the uppermost factor for grounding resistance in most conditions. The grounding resistance decreases rapidly when the depth of seawater increases from 0 to 2 $\mathrm{m}$. And when the depth of seawater is greater than $5 \mathrm{~m}$, the grounding resistance is stable as the other effecting factors keep constant. Another two factors, the thickness of clay layer and the resistivity of gravel, will make more effects for grounding resistance in the case of shallow seawater. When offshore WTs are near to the coast, the resistance may exceed the specified value for the WTs on land. The values and distribution of potential on the sea surface are calculated and mapped out. Changing the influential factors will change the distribution of potential. Even for the grounding resistance is relatively small, the potential still achieve high level. The series of conclusions obtained by the GSSAS simulation have practical engineering significance and can provide a basic reference for the design of offshore wind turbines.

This work was partly supported by National Natural Science Foundation of China under Grant No. 51420105011.

\section{References}

1. Duan Y F, Ran H Y, Feng-Li L I. Design of Foundation for Offshore Wind Field[J]. Journal of Water Resources \& Architectural Engineering, 2010.

2. Wei K, Yuan W. Nonlinear Analysis of Offshore Jacket Structures including Ductility of Welded Tubular Connections[C]// International Conference on Smart City and Systems Engineering. IEEE Computer Society, 2016:128-132.

3. Malcolm N, Aggarwal R. Analysis of transient potential phenomena due to direct lightning strikes on wind turbine blade[C] IEEE Power \& Energy Society General Meeting. IEEE, 2014:1-5.

4. Gibson R E, Dowse B E W. The influence of geotechnical engineering on the evolution of offshore structures in the North Sea[J]. Canadian Geotechnical Journal, 2011, 18(2):171-178.

5. Nagao $M$, Nagaoka $N$, Baba $Y$, et al. FDTD Analysis of the Current Distribution within the Grounding System for a Wind Turbine Generation Tower Struck by Lightning[J]. Ieej Transactions on Power \& Energy, 2008, 128(11):1393-1400.

6. Chow, Y.L, Yang, J.J, Srivastava, K.D. Grounding resistance of buried electrodes in multi-layer earth predicted by simple voltage measurements along earth surface -- A theoretical discussion[J]. IEEE 
Transactions on Power Delivery, 1995, 10(2):707 715 .

7. Cong L, Zhang X Q. Study on calculation of grounding resistance of wind turbine[J] .Electric Technology, 2015(17):44-48.

8. GB 50169-2006. Code for construction and acceptance of earthed device electric equipment installation engineering[S]. 2006

9. Yang W B, Zhou H. Design for potential protection and lightning grounding of wind turbine[J]. High Voltage Engineering, 2008.

10. Zhao H X, Wang X R. Lightning Stroke Mechanism of Wind Turbines and Its Lightning Protection measures [J]. Power System Technology, 2003, $07: 12-15+39$.

11. Tao S, Zhang X, Huang K. A simulation exploration on the grounding characteristic of monopile foundation offshore wind turbines[J]. Journal of Renewable \& Sustainable Energy, 2016, 2004, 28(4): 27-29

12. Zheng Z N, Wang J G, Fan Y D, et al. Grounding Impedance Calculation of Steel Monopile Foundations of Offshore Wind Turbines in Intertidal Zone[C]// Iclp. 2014:946-949.
13. DeVries W. Assessment of bottom-mounted support structure types with conventional design stiffness and installation techniques for typical deep-water sites. Upwind Research Report D, vol. 4 (2007) pp. $1-76$

14. DNV-OS-J101. Design of offshore wind turbine structures[S]. 2004

15. Dier A F, Hellan O. A Non-Linear Tubular Joint Response Model for Pushover Analysis[C]// ASME 2002 21st International Conference on Offshore Mechanics and Arctic Engineering. American Society of Mechanical Engineers, 2002:627-634.

16. Vorpahl F, Popko W, Kaufer D. Description of a basic model of the "UpWind reference jacket" for code comparison in the OC4 project under IEA Wind Annex XXX[J]. 2013.

17. IEC62305-1, Protection against lightning-Part 1: General principles. 2006.

18. IEC 61400-24, Wind turbine generator systems-Part 24: Lightning protection, 2010.

19. National Standards of the People's Republic of China, GB50057-2010, Design Code for Protection of Structures against lightning. Beijing, China Plan publishing House, 2010. 